\title{
CONCEPTUAL BASES OF PSYCHIATRY FOR THE PERSON
}

\section{Ethnomedical and cultural foundations of psychiatry for the person}

\author{
Horacio Fabrega Jr MD ${ }^{a}$ and Ronald Wintrob $M^{b}$ \\ a Professor of Psychiatry and Anthropology, University of Pittsburgh, Pittsburgh, Pennsylvania, USA \\ b Clinical Professor of Psychiatry and Human Behavior, Warren Alpert School of Medicine, Butler Hospital, \\ Brown University, Providence, Rhode Island, USA
}

\section{Keywords}

Ethonmedicines, clinical psychiatrists, cultural psychiatry

Correspondence Address

Prof. Horacio Fabrega Jr., Department of Psychiatry, Western Psychiatric Institute, University of Pittsburgh, 3811 O’Hara

Street, Pittsburg PA15213, USA. E-mail: hfabregajr@verizon.net

Accepted for Publication: 19 January 2011

\section{Introduction}

Ethnomedicine highlights the cultural framework in terms of which societies understand and shape the subjective experiences of sickness and healing [1]. As social and cultural institutions, ethnomedicines evolve and function through inclusion of diverse forms of sickness, including symptomatic expressions of both physical and emotional concomitants of distress. The symptomatic expressions of physical and emotional concomitants of distress are the principal focus of clinical psychiatrists and of other clinicians in fields closely related to psychiatry, in their efforts to help relieve the distress of their patients. Such symptoms are manifestations of peoples' fears of all the types of misfortunes that can befall individuals, their families and communities; fears relating as much to supernatural influences as to the natural world order, to fears of malign magic, fate and divine punishment for evil thoughts and deeds, as much as to fears of flood, earthquake, drought and fire.

As a clinical discipline, cultural psychiatry is concerned with both the intra-cultural and cross-cultural variations in the physical and emotional concomitants of distress. The history of ethnomedicine and cultural psychiatry reinforces the claim that the diverse needs of persons experiencing distress are central concerns of psychiatric practice [2].

\section{Evolutionary History of Psychiatry Discloses Concern for Persons.}

Sickness and healing started out as individual and family responses to perceived dis-ease and distress and evolved in relation to culture, language and cognition to form communal, and then societal, ethnomedicines. They embodied forms of altruism and moral humanitarian concern for the plight of individuals who exhibited symptoms of both physical and emotional distress. Ancient academic traditions of medicine, medical anthropology study of contemporary non-literate societies, and knowledge drawn from study of religious/spiritual healing attest to a focus on humanistic concern for persons exhibiting such symptoms [3-5].

\section{Modern Psychiatry's Default Position: Scientific Objectivism}

Modern medicine's basis is nomothetic/idiographic dualism: a) abstract concepts and deductive axioms represent valid ways of formulating clinical tasks of diagnosis and practice and are b) logically separable from an interpretative viewpoint that focuses on historical and cultural formulations of experience and behavior [6]. Ethnomedicines construe people's descriptions of their physical and emotional distress as personal and family dilemmas of moral, spiritual, and biological significance. The history of modern psychiatry reinforces personcentered concerns [7]. Heavy reliance on 
nomothetic/idiographic dualism risks blurring psychiatry’s ethnomedical foundations.

\section{The Challenge of Clinical Neuroscience Psychiatry}

Research involving psychiatric epidemiology, population genetics, and related biological sciences indicates that major psychiatric disorders represent human universals [8]. It implies a pan-cultural and trans-historical focus of ethnomedicines on descriptions of physical and emotional distress. Neuroscience's objective of understanding brain/behavior correlates at the molecular level might lead to circumventing the equally important appreciation of the diverse emotional needs and psychosocial identities of persons.

\section{Ethnomedicine and Cultural Psychiatry Encompass Personal Concerns.}

The neuroscience focus on the molecular and the genetic data could be analogized as the microscopic examination of human suffering, in contrast with the more 'telescopic' view of ethnomedicine and cultural psychiatry's focus on societies, communities, tribes and families, and on global issues that have an impact on the mental health of the world's population. Included in this global 'telescopic' perspective are issues such as the global economic and social burden of all forms of illness disease, as well as the impact of global population migration due to civil turmoil, war, natural disaster, climate change, and economic recession.

Contemporary societies everywhere accept and utilize science and medicine, in both their theory and application, while at the same time continuing to accept and utilize non-scientific 'traditional', folk, religious, 'complimentary' and 'alternative' approaches to avoid falling victim to misfortune, illness and trauma of all sorts, and to cope with those misfortunes that inevitably affect them, their families and communities. This is as true of contemporary 'western' societies as it is, and always has been, in all other societies. Both pre-literate and postliterate societies embrace and utilize a wide range of technologies and practices in their determination to cope with all the manifestations of misfortune, sickness, illness, trauma and disease to which they are exposed.

A powerful example is available in contemporary American society, where the evidence shows that vast sums of energy and money are expended by both the highly educated and the less "technologically sophisticated" throughout the country, on 'Complimentary and Alternative Medicine' as well as on folk, faith and religious healing traditions and practices. This applies as much to the majority 'white' segment of the American population as it does to the African American, Hispanic American, Asian American and Native American components of the national population [9].
Virtually all non-western Great Medical Traditions involve metaphysical as well as naturalistic dimensions; for example, those of China and India, of the Aztec, Mayan and Quichua of central and south America, the Navajo, Hopi, Cree, Algonkian, Kwakiutl and numerous other North American 'first nations', of the Maori of New Zealand and the Aboriginal tribes of Australia [9]. All ethnomedicines rest on culturally sensitive formulations of sickness and healing exemplified as humanistic, moral considerations involving persons and their life circumstances $[3,10]$.

\section{Cultural Meaning Systems}

Conditions of interest to psychiatry and its related clinical and social science disciplines can be consciously recognized by those who experience them, or they can be non-conscious. If conscious, manifestations can be seen as good or bad, normal or abnormal; and other people in their affiliative group may use similar labels. If recognized by individual or significant others it can give rise to a need for redirection and/or corrective action. The important point is that psychiatric disorder as defined by a psychiatrist is not necessarily recognized as such by people who do not share the psychiatrist's scientific worldview. Those people, whether they are living in high income or low income countries, in countries and communities characterized as highly industrialized and technically advanced, or as agrarian and 'developing', may not identify their symptoms of distress as a psychological problem, social deviancy or medical pathology. Furthermore, even if their symptoms of distress are accorded special significance culturally, they are not necessarily condemned or discredited [10,11].

The reality is that throughout many centuries of cultural history, conceptions about self and reality did not exemplify contemporary scientific and medical dualisms; for example, mind/body, natural/supernatural or occult, experience/behavior, language/reality, or science/spirituality. The world always has, and continues to be, populated by culturally diverse populations that do not subscribe to what could be considered reductionist, or contemporary 'dualist' conceptions of persons and their distress, among whom religion and spirituality retain overriding significance. Approaches to diagnosis and practice should exemplify the crucial influence of diverse systems of meaning in determining how self is construed and played out $[12,13]$. Connecting psychiatry to its ethnomedical roots helps clinicians as well as investigators turn their attention to all dimensions of dis-ease, pain and suffering, and to a renewed emphasis on related humanistic concerns. 


\section{Concluding comments}

The humanistic content of conditions of psychiatric interest which are embraced in other contemporary ethnomedical traditions can not only be bypassed, but their authenticity and cultural significance undermined by a simplistic application and strong political appeal of biological reductionism [2]. There is ample justification for construing and assessing conditions of psychiatric interest in ways that affirm the cultural diversity of the person $[14,15]$.

\section{References}

[1] Fabrega H Jr: (1975). The need for an ethnomedical science. Science 189: 969-975.

[2] Mezzich JE, Caracci G, Kirmayer L, Fabrega H: Cultural (2009). Formulation Guidelines. Transcultural Psychiatry, 46: 383-405.

[3] Fabrega H Jr (1997). Evolution of Sickness and Healing. Berkeley: University of California Press.

[4] Fabrega H Jr (2000). Culture, spirituality and psychiatry. In; Current Opinion in Psychiatry 13:525-530.

[5] Fabrega H Jr (2006) Why Psychiatric Conditions are Special: An evolutionary and cross-cultural perspective. Perspective in Biology and Medicine 49: 586-601.

[6] Bryant JM (2004). An evolutionary social science? A skeptic's brief, theoretical and substantive. Philosophy of the Social Sciences. 34: 451-492.

[7] Fabrega H Jr (1989). An ethnomedical perspective of AngloAmerican psychiatry. American Journal of Psychiatry 146: 588596.

[8] Keller M.C. and Miller G. (2006). Resolving the paradox of common, harmful, heritable disorders: which evolutionary models work best? Behavioral and Brain Sciences 29, 385-452,

[9] Wintrob R (2009). Overview: Looking Toward the Future of Shared Knowledge and Healing Practices. In: Psychiatrists and Traditional Healers; Unwitting Partners in Global Mental Health. Eds; Mario Incayawar, Ronald Wintrob, Lise Bouchard. Wiley-Blackwell, Chichester, UK.

[10] Fabrega H Jr (2009) History of Mental Illness in India: A Cultural Psychiatry Retrospective. Motilal Banarsidass, Delhi, India.

[11] Varma V K, Kala A K, Gupta N (2009). Culture Personality and Mental Illness: A Perspective of Traditional Societies. Jaypee Brothers; New Delhi.

[12] Group for the Advancement of Psychiatry; Committee on Cultural Psychiatry: Cultural Assessment in Clinical Psychiatry. American Psychiatric Press, Washington DC, 2001.

[13] Kohn R and Wintrob R: Research Advances in the Relationship Between Immigration and Psychiatric Disorders. In: Advances in Psychiatry, Vol 3. Eds; George Christodoulou, Miguel Jorge, Juan Mezzich,; Athens, World Psychiatric Association, 2009.

[14] Mezzich J E (2007). Psychiatry for the Person: Articulating Medicine’s Science and Humanism. World Psychiatry 6: 1-3.

[15] Kohn R, Wintrob RM and Alarcon RD: Transcultural Psychiatry. In; Comprehensive Textbook of Psychiatry, Vol 9. Ed; Benjamin J Sadock, Virginia A Sadock, Pedro Ruiz. Lippincott, Williams and Wilkins, Philadelphia 2009 pp 735-753. 